Article

\title{
Concentration in Saliva and Antibacterial Effect of Xylitol Chewing Gum: In Vivo and In Vitro Study
}

\author{
Fabio Cocco ${ }^{1}$, Maria Grazia Cagetti ${ }^{2} \mathbb{D}$, Osama Majdub ${ }^{1}$ and Guglielmo Campus ${ }^{1,3, * \mathbb{C}}$ \\ 1 Department of Surgery, Medical and Experimental Sciences-School of Dentistry, University of Sassari, \\ Viale San Pietro 43/C, I-07100 Sassari, Italy; dr.fabiococco@gmail.com (F.C.); \\ osama.majoudub1@gmail.com (O.M.) \\ 2 Department of Biomedical, Surgical and Dental Sciences, University of Milan, Via Beldiletto 1, \\ 20142 Milan, Italy; maria.cagetti@unimi.it \\ 3 Department of Restorative, Preventive and Pediatric Dentistry, University of Bern, Freiburgstrasse 7, \\ Sw-3010 Bern, Switzerland \\ * Correspondence: guglielmo.campus@zmk.unibe.ch; Tel.: +41-031-664098
}

Received: 18 March 2020; Accepted: 20 April 2020; Published: 22 April 2020

\begin{abstract}
Purpose. The saliva concentration of xylitol released from two chewing gums was recorded, the first containing xylitol as the only sweetener $(100 \%$ xylitol) and the second containing only $22 \%$ of the polyol. In addition, the in vitro antibacterial effect of the two chewing gums was evaluated. Materials and Methods. The salivary concentration of Xylitol in 32 subjects was determined before and at $0.30,1.00,2.00,5.00$, and $10.00 \mathrm{~min}$ while using the chewing gums, and at 15.00, 20.00, and $25.00 \mathrm{~min}$ after the gums were discarded. In vitro antibacterial activity was determined on a pooled subgingival plaque sample obtained from four patients with periodontal disease. Cariogenic and periodontal bacteria were evaluated before and $15 \mathrm{~min}, 60 \mathrm{~min}$, and $24 \mathrm{~h}$ after gum contact. Results. Using the $100 \%$ xylitol chewing gum, saliva levels increased bimodally, one peak after $30 \mathrm{~s}(1.49 \pm 1.41 \mathrm{log} \mu \mathrm{g} / \mathrm{L})$ and a second one at a $10-\mathrm{min}$ evaluation $(1.41 \pm 1.11 \log \mu \mathrm{g} / \mathrm{L})$; the $22 \%$ chewing gum peaked only two minute after contact $(1.21 \pm 1.24 \log \mu \mathrm{g} / \mathrm{L})$. Overall, a statistically significantly higher salivary concentration of xylitol was detected using the $100 \%$ xylitol gum. All bacteria decreased after the addition of the two chewing gums; the $100 \%$ gum achieved a greater decrease than the $22 \%$ gum. Conclusion. The use of both chewing gums increased the concentrations of xylitol in saliva, with a statistically significantly higher concentration using the $100 \%$ xylitol gum. Cariogenic and periodontal bacteria were reduced by both chewing gums; $100 \%$ xylitol gum produced the highest and longest lasting effect. This study opens up to the use of xylitol against periodontal disease.
\end{abstract}

Keywords: xylitol; saliva; oral bacteria; sub-gingival plaque; antimicrobial effect; chewing gum

\section{Introduction}

Dietary fermentable carbohydrates are among the main triggers for the development of cariogenic biofilm [1]. Several preventive strategies are recommended to control the risk of caries; dietary changes, with reduce intake of sweetener and the use of sugar substitutes, are probably among the most suggested [2].

Several benefits of polyols, particularly xylitol, have been suggested for general and oral health, such as increasing tight junction and barrier formation of the skin, modulating intestinal microbial composition, reducing nose, throat, and ear bacterial infections, influencing bone health, stimulating immunity, and increasing metabolic health [3].

Consumption of polyol, particularly xylitol, through chewing gum or tablets, is reported to reduce dental plaque, the concentration of cariogenic bacteria, such as mutans streptococci, leading to a 
reduced caries increment [4,5]. Although the xylitol mechanism is not fully known, several studies demonstrate the benefits on caries both in children and adults, showing that the polyol possesses both noncariogenic and cariostatic properties. The supposed effective daily dose of xylitol is between three and eight grams and frequent and prolonged intakes are recommended to obtain long-lasting benefits [2]. The anti-caries effect of xylitol is associated with suppression of mutans streptococci and modification of their virulence $[5,6]$.

When xylitol is administered, the frequency of administration, the dose-response, and the minimal salivary concentration are important parameters that have to be assessed. However, only afew studies have evaluated the concentration of polyol in saliva after the intake of products containing xylitol, with discordant results [7-9]. Since there are no clear indications of salivary concentrations after the intake of different products, this can lead to using these products in a way that is not optimal for achieving the complete release of xylitol (e.g., mastication time of chewing gum might be not sufficient to ensure the complete release of the polyol); it is of high relevance to obtain reliable data on salivary xylitol concentrations.

While a fairly large number of studies have been conducted on the effect of xylitol administration on caries-associated bacteria [9-12], few studies include the effects of this polyol on other oral strains, such as those associated to periodontal disease [13,14]. In these studies, although xylitol consumption has been shown to reduce the streptococci counts, it has not affected the bacterial composition of the dental plaque. Therefore, the acquisition of information on the antibacterial activity of xylitol on different bacteria strains (i.e., periodontal bacteria and other oral saprophytes) is of extreme interest.

This work aimed at assessing the salivary concentration of xylitol released from two chewing gums containing different amounts of the polyol in a sample of healthy volunteers. In addition, the in vitro antibacterial effect of xylitol chewing gum was tested against different strains of oral microorganisms related to caries and periodontal disease.

\section{Materials and Methods}

\subsection{Study Design}

This study took place in Sassari (Italy) and lasted from February 2018 to May 2018. The study was approved by the Ethics Committee of the University of Sassari (SS-15884-GC 23/ 09/2017) and registered at http://www.clinicaltrial.gov (Protocol Registration Receipt NCT03971981) and conducted in accordance with the Declaration of Helsinki (http://www.wma.net).

The research protocol was conducted in two phases (Figure 1). In the first, an in vivo double-blind cross-over study was performed to measure the salivary concentration of xylitol released from two types of chewing gum containing different amounts of the polyol. The study had a cross-over design: the first half of the sample used the chewing gum with xylitol as the only sweetener $(100 \%$ xylitol chewing gum) and the other half used the chewing gum with xylitol among the sweeteners (22\% xylitol chewing gum); after a 7-day wash-out period, the two sub-groups reversed the types of chewing gum. Subjects were instructed to consume the products as they normally do. Throughout the study the subjects were not allowed to use mouthwashes, other xylitol products, antimicrobial medications, etc. In the second phase of the designed protocol, the antibacterial efficacy of the two types of chewing gum was tested in vitro against nine different strains of oral bacteria. 
Phase in vivo: Salivary concentration of Xylitol $\mathrm{N}=32$ subjects

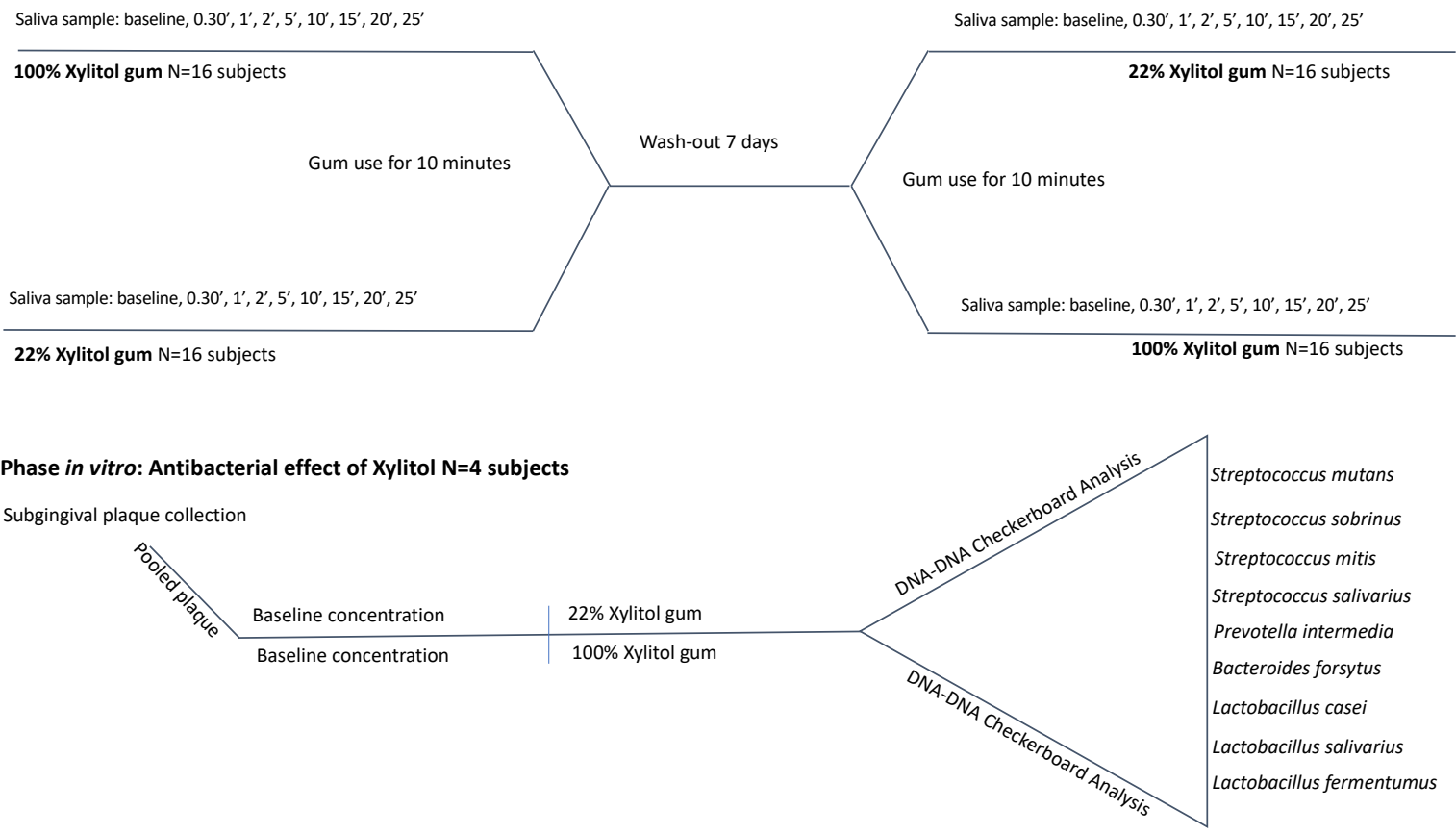

Figure 1. Flow-chart of the study design (in vivo and in vitro phases).

All chewing gum used in this investigation were produced and supplied by Perfetti Van Melle SpA (Lainate, Italy) and are commercially available in Italy. Except for the sweeteners, the two chewing gums were identical in weight $(1.4 \mathrm{~g})$, shape, color, and packaging. Their composition is displayed in Table 1.

Table 1. Percentage Composition of the two chewing gums. Each chewing gum weights 1.4g.

\begin{tabular}{ccc}
\hline Ingredients & $\mathbf{1 0 0} \%$ Xylitol & $\mathbf{2 2 \%}$ Xylitol \\
\hline & $\mathrm{g} / \%$ & $\mathrm{~g} / \%$ \\
\hline Xylitol & $0.903 / 64.5$ & $0.308 / 22$ \\
Sorbitol & - & $0.434 / 31$ \\
Maltitol Syrup & - & $0.084 / 6$ \\
Mannitol & - & $0.056 / 4$ \\
Gum base & $0.421 / 30.1$ & $0.392 / 28$ \\
Other components & $0.076 / 5.4$ & $0.126 / 9$ \\
\hline
\end{tabular}

The xylitol amount was entirely contained in the hard coating for the $22 \%$ chewing gum, while the $100 \%$ xylitol gum contained the same amount in the hard coating and the remaining part in the gum pellet.

\subsection{Xylitol Concentration In Saliva}

\subsubsection{Sample Size}

In the literature, only a few studies reported data on the concentration of xylitol in saliva [7-9]. Since no study reported a sample size calculation and two of them have a very small number of participants, it was decided to use the study performed in Finland as reference [9]. Since the present study has a double-blind cross-over design, the sample size calculation was performed through $G^{*}$ Power 3.1.3 for Apple, using logistic regression with an odds ratio of 1.8 and an error probability of 0.04 . The minimum sample size was set to 28 subjects; the number was then increased taking into account the uncertainty of the effect and the no-responders rate; the number of subjects was set to 38 . 
Fifty dental students (age range 19-25 years), attending the Dental School of the University of Sassari, were invited to participate with a leaflet explaining the purpose of the study together with an informed consent; thirty-three accepted. The inclusion criteria were good general health, absence of diseases that could alter the saliva secretion rate, as assessed by a medical questionnaire, a stimulated saliva flow of at least $1 \mathrm{~mL} / \mathrm{min}$, and no medication in the six weeks before the beginning of the study. Smokers were not included. One of the authors (OM) performed all the examinations and registered medical and dental histories.

\subsubsection{Samples Collection and Measurements of the Concentration of Xylitol in Saliva}

The saliva flow rate was measured in the mid-morning at least one hour after each participant had taken any food. Subjects were asked to chew a piece of paraffin wax for $1 \mathrm{~min}$ and then spit into graduated tubes for $5 \mathrm{~min}$. Thirty-two subjects showed a saliva flow $\geq 1 \mathrm{~mL} / \mathrm{min}$ and were finally enrolled.

Xylitol concentration was determined through a spectrophotometer analysis (Agilent Technologies Cary $60 \mathrm{UV}$-Vis, using a wave-length of $492 \mathrm{~nm}$ ) in saliva samples collected before and during chewing gum use at $0.30,1.00,2.00,5.00$, and $10.00 \mathrm{~min}$ (stimulated saliva sampling); then the chewing gums were discarded and further samples were collected at 15.00, 20.00, and $25.00 \mathrm{~min}$ from the start of chewing (unstimulated saliva sampling). A minimum of $0.5 \mathrm{~mL}$ of saliva was collected at each time point.

The concentration of xylitol was determined by the oxidation of nicotinamide-adenine dinucleotide (NAD+) to D-xylulose in the presence of xylitol dehydrogenase (SDH) with the formation of reduced nicotinamide-adenine dinucleotide (NADH) [15]. Saliva samples were first de-proteinased adding to a $200 \mu \mathrm{L}$ of saliva an equal volume of ice-cold $1 \mathrm{M}$ perchloric acid and centrifuged at $1500 \mathrm{~g}$ for $10 \mathrm{~min}$ and the supernatant was then neutralized with $1 \mathrm{M} \mathrm{KOH}$. The sample obtained was treated as follows: $200 \mu \mathrm{L}$ of the sample was added to $10 \mu \mathrm{L}$ of distilled water in a sterile 1.7-mL Eppendorf tube followed by $50 \mu \mathrm{L}$ of buffer solution ( $\mathrm{pH}$ 8.6). Then $20 \mu \mathrm{L}$ of NADH iodonitrotetrazolium chloride and $0.2 \mu \mathrm{L}$ of diaphorase were put into the solution. The reaction started with the addition of $0.5 \mu \mathrm{L}$ of $\mathrm{SDH}$. The absorbance of the solutions was read at the end of the reaction (approx. $15 \mathrm{~min}$ ). Formazan crystals were dissolved by addition of $0.5 \mathrm{~mL}$ of lysing solution, and after a 3-h incubation at room temperature, $100 \mu \mathrm{L}$ of the suspension was added to each sample that was measured by the increase in absorbance at $492 \mathrm{~nm}$. The smallest differentiating absorbance for the assay is 0.005 absorbance units. All salivary Xylitol concentration data were expressed in $\mu \mathrm{g} / \mathrm{mL}$.

\subsection{Antibacterial Activity of Xylitol}

The in vitro antibacterial activity of the two types of xylitol chewing gum at different concentrations ( $22 \%$ and $100 \%$, respectively) was determined on a sub-gingival pooled plaque sample collected from four patients affected by periodontal disease attending the Periodontal Department of the Dental Clinic of the University of Sassari. An informed consent, explaining the purpose of the study, was obtained from the four volunteers.

\subsubsection{Methods}

None of the subjects used antibiotics or had undergone periodontal treatment during the 4 months before the sampling; participants were required to refrain from eating, drinking, smoking, or brushing their teeth after midnight on the day of the sampling. The volunteers rinsed their mouth with water, and the deepest pocket (4-7 mm range of pocket dept and 1-2 $\mathrm{mm}$ of attachment level) of each quadrant was chosen for sub-gingival plaque sampling. The sites of collection were isolated with cotton rolls, and supragingival plaque was gently removed with curettes and dried with air. Sub-gingival plaque was taken by the insertion of sterile paper points for $15 \mathrm{~s}$. The paper points were transferred to $250 \mathrm{~mL}$ of reduced transport fluid (RTF) [16,17], and vortexed together for $30 \mathrm{~s}$; the supernatant and the paper points were removed and the pellet re-suspended in $100 \mathrm{~mL}$ of twice-distilled water. Aliquots were 
measured in a spectrophotometer in 1 -mL cuvets (one optical density unit was considered $\approx 10^{9}$ cells $/ \mathrm{mL}$ at $600 \mathrm{~nm}$ ). Twenty $\mathrm{g} / \mathrm{L}$ trypticase soy agar (Sigma-Aldrich, Italy), $26 \mathrm{~g} / \mathrm{L}$ brain-heart infusion (BHI) agar (Difco, USA), $10 \mathrm{~g} / \mathrm{L}$ yeast extract, $5 \mathrm{mg} / \mathrm{L}$ hemin, and $20 \%$ sucrose $(\mathrm{w} / \mathrm{v})$ were mixed to prepare a medium. After sterilization and cooling, $5 \%$ defibrinated sheep blood, $5 \mathrm{mg} / \mathrm{mL}$ menadione, and $10 \mathrm{mg} / \mathrm{mL} \mathrm{N}$-acetylmuramic acid (Sigma-Aldrich, Italy) were aseptically added; $150 \mathrm{~mL}$ of the medium was then dispended into one 96 -well microtiter plate (Cellstar, Italy). The plaque broth $(150 \mu \mathrm{L}$, or $\% 1.5 \cdot 10^{6}$ bacteria) was pipetted to fill into the blood agar wells. The plates were then incubated anaerobically at $35^{\circ} \mathrm{C}$ for $48 \mathrm{~h}$, then the cultures were blotted out and the wells gently washed three times with sterile PBS in order to remove nonadherent cells; this operation was repeated [16].

\subsubsection{Specimen Preparation}

Three samples of each chewing gum were grinded in a mortar with $30 \mathrm{~mL}$ of artificial saliva (1.5 mM CaCl2, $1.0 \mathrm{mM} \mathrm{KH} 2 \mathrm{PO} 4$ and $50 \mathrm{mM} \mathrm{NaCl}, \mathrm{pH}$ 7.0) [18], during $5 \mathrm{~min}$, then the final solution was collected in a clean container. An amount of $2 \mathrm{ml}$ of the solution were inserted in the wells. Twenty-four wells were evaluated before adding the solution and then another 24 wells after $15 \mathrm{~min}$, $60 \mathrm{~min}$, and $24 \mathrm{~h}$ from the contact between the plaque sample and the chewing gum solution. Tris-EDTA buffer $(1.5 \mathrm{~mL})$ was added to the plates and the bacterial colonies were scraped off the surface with sterile L-shaped glass rods. The suspensions were placed into individual tubes (Cellstar, Italy) and sonicated for $10 \mathrm{~s}$. Each suspension was adjusted to a final optical density of 1.0, which corresponded to $\% 10^{9}$ cells.

\subsubsection{Microbiological Analysis}

The analysis of bacterial species was performed using the checkerboard DNA-DNA hybridization method [19-21]. Whole genomic probes were prepared from nine bacterial strains that are part of supra and subgingival plaque biofilm, some of them related to caries, gingivitis, and periodontal disease (S. mutans, S. sobrinus, P. intermedia, S. salivarius, S. mitis, B. forsythus, L. casei, L. salivarius, and L. fermentum) [22,23]. An evaluation of the bacterial counts in the samples was performed by comparing the obtained signals with the ones generated by the pooled standard samples containing a count of $10^{6}$ and $10^{5}$ of each bacterial species, respectively. The signals were coded on a scale from 0 to 5 as follows: $0=$ no signal; $1=$ a signal density weaker than that of the low standard $\left(<10^{5}\right.$ bacteria $)$; $2=$ a signal density equal to that of the low standard $\left(=10^{5}\right.$ bacteria $) ; 3=$ a signal density higher than that of the low standard but lower than that of the high standard $\left(>10^{5}\right.$ but $<10^{6}$ bacteria); $4=$ a signal density equal to that of the high standard $\left(=10^{6}\right.$ bacteria); and $5=$ a signal density higher than that of the high standard $\left(>10^{6}\right.$ bacteria). Further details regarding the technique might be found in the literature [24,25].

\subsection{Data Analysis}

All data from both phases were imported into MS Excel and checked. From a brief analysis, the salivary xylitol concentrations appeared with a high skewness, so to normalize the data, they were logarithmically transformed before the analysis. Mean and standard deviation ( \pm SD) for each sampling point and the checkerboard scores were calculated using STATA 13 (StataCorp LLC, USA). The comparison between the two types of chewing gum at each sampling time was performed using one-way Analysis of Variance (ANOVA), while the intra-group comparison was evaluated with two-way ANOVA. Due to the variability of the salivary concentration among subjects, the internal-consistency reliability was calculated using Cronbach's alpha statistic as post-hoc evaluation. The data set is available in the Supplementary Materials. The level of statistical significance was set at $5 \%$. 


\section{Results}

No statistically significant differences were found in the xylitol concentration of saliva samples collected before the use of the chewing gums (Table 2).

Table 2. Xylitol concentrations in saliva $(\mu \mathrm{g} / \mathrm{L})$. One-way ANOVA for the comparison between the two types of chewing gum and two-way ANOVA for intra-group comparison. The values in bold are the maximum peaks reached.

\begin{tabular}{cccc}
\hline Time & $\mathbf{1 0 0} \%$ Xylitol $(\log \mu \mathrm{g} / \mathrm{L})$ & $\mathbf{2 2} \%$ Xylitol $(\log \mu \mathrm{g} / \mathrm{L})$ & $\boldsymbol{p}$-Value \\
\hline & Mean $\pm \mathrm{sd}$ & mean $\pm \mathrm{sd}$ & \\
Before & $-0.68 \pm-0.66$ & $-0.66 \pm-0.41$ & $\mathrm{NS}$ \\
$30 \mathrm{~s}$ & $1.49 \pm 1.41$ & $0.04 \pm 1.20$ & $<0.01$ \\
$1 \mathrm{~min}$ & $1.39 \pm 1.53$ & $1.19 \pm 1.38$ & 0.02 \\
$2 \mathrm{~min}$ & $1.09 \pm 1.27$ & $1.21 \pm 1.24$ & 0.03 \\
$5 \mathrm{~min}$ & $1.28 \pm 1.10$ & $1.00 \pm 1.19$ & 0.02 \\
$10 \mathrm{~min}$ & $1.41 \pm 1.11$ & $0.45 \pm 0.64$ & $<0.01$ \\
$15 \mathrm{~min}$ & $1.19 \pm 1.12$ & $-0.08 \pm 0.25$ & $<0.01$ \\
$20 \mathrm{~min}$ & $1.07 \pm 1.03$ & $-0.33 \pm 0.01$ & 0.02 \\
$25 \mathrm{~min}$ & $-0.30 \pm-0.92$ & $-0.92 \pm-1.15$ & $<0.01$ \\
$\mathrm{p}$-value & $<0.01$ & $<0.01$ & \\
\hline
\end{tabular}

The $100 \%$ xylitol chewing gum produced the highest salivary concentration after $30 \mathrm{~s}$ of use $(1.49 \pm 1.41 \log \mu \mathrm{g} / \mathrm{L})$ and then the amount decreased after 1 and $2 \mathrm{~min}$ until a second increment was detected at 5 and $10 \mathrm{~min}(1.28 \pm 1.10 \log \mu \mathrm{g} / \mathrm{L}$ and $1.41 \pm 1.11 \log \mu \mathrm{g} / \mathrm{L}$, respectively); after that, a slow decrease until $25 \mathrm{~min}$ was found. The $22 \%$ xylitol chewing gum produced the highest salivary concentration after $2 \mathrm{~min}$ of use $(1.21 \pm 1.24 \log \mu \mathrm{g} / \mathrm{L})$ and then gradually decreased in the following evaluations. Statistically significant differences between the concentrations produced by the use of the two Xylitol chewing gums were recorded at all time points $(p=0.01$ for the comparison after $1 \mathrm{~min}$, while $p<0.01$ for all the other times). The modification of the concentration of xylitol in each group during the different times was statistically significant $(p<0.01)$. The Cronbach alpha was 0.97 in the $100 \%$ xylitol group and 0.95 in the $22 \%$ Xylitol group.

The bacterial concentrations before and after the contact with the two xylitol chewing gums (22\% and $100 \%$ xylitol) solutions are reported in Table 3. All the considered bacterial strains decreased after the addition of the two chewing gums solutions. The $22 \%$ xylitol obtained the highest decrease (except for B. forsythus) after $60 \mathrm{~min}$ and then increased again at the last evaluation (24 h); the 100\% xylitol chewing gum obtained a greater decrease compared to the $22 \%$ xylitol at all time points; the highest decrease was recorded after $24 \mathrm{~h}$ from the contact for all bacteria strains. 
Table 3. Mean concentration ( $\pm \mathrm{SD}$ ) of bacteria in sub-gingival plaque based on analysis of a 5 -unit score. $\left(1=<10^{5}, 2=10^{5}, 3=10^{5}>\mathrm{x}<10^{6}, 4=10^{6}, 5=>10^{6}\right)$

\begin{tabular}{|c|c|c|c|c|c|c|c|c|c|}
\hline \multirow[t]{2}{*}{$\begin{array}{l}\text { Bacteria } \\
\text { Strain }\end{array}$} & \multirow[t]{2}{*}{$\begin{array}{c}\text { Pre } \\
\text { Mean (SD) }\end{array}$} & \multicolumn{2}{|c|}{$\begin{array}{c}15 \text { min } \\
\text { Mean (SD) }\end{array}$} & \multicolumn{2}{|c|}{$\begin{array}{c}60 \text { min } \\
\text { Mean (SD) }\end{array}$} & \multicolumn{2}{|c|}{$\begin{array}{c}24 \mathrm{~h} \\
\text { Mean (SD) }\end{array}$} & \multicolumn{2}{|c|}{ p-Value } \\
\hline & & 100\% Xylitol & $22 \%$ Xylitol & $100 \%$ Xylitol & $22 \%$ Xylitol & 100\% Xylitol & $22 \%$ Xylitol & $100 \%$ Xylitol & $22 \%$ Xylito \\
\hline S. mutans & $3.49 \pm 1.08$ & $1.76 \pm 0.60$ & $3.15 \pm 0.65^{\wedge}$ & $1.32 \pm 0,47$ & $2.82 \pm 0.72^{\wedge}$ & $1.21 \pm 0.43$ & $2.96 \pm 0.56^{\wedge}$ & $\mathrm{p}<0.01$ & $p=0.04$ \\
\hline S. sobrinus & $2.00 \pm 0.65$ & $1.20 \pm 0.41$ & $1.60 \pm 0.70$ * & $1.11 \pm 0.32$ & $1.47 \pm 0.66$ & $1.06 \pm 0.24$ & $1.74 \pm 0.66^{\circ}$ & $p=0.04$ & $p=0.02$ \\
\hline P. intermedia & $2.69 \pm 1.12$ & $1.68 \pm 0.64$ & $2.34 \pm 0.82^{\circ}$ & $1.53 \pm 0.61$ & $1.95 \pm 0.81$ * & $1.29 \pm 0.46$ & $2.29 \pm 0.71$ & $p<0.01$ & $p=0.05$ \\
\hline S. salivarius & $2.11 \pm 0.92$ & $1.56 \pm 0.50$ & $1.84 \pm 0.69$ & $1.32 \pm 0.47$ & $1.69 \pm 0.61$ & $1.20 \pm 0.41$ & $1.91 \pm 0.56^{\circ}$ & $p=0.02$ & $p=0.07$ \\
\hline S. mitis & $2.46 \pm 1.11$ & $1.56 \pm 0.66$ & $1.90 \pm 0.75 *$ & $1.41 \pm 0.56$ & $1.78 \pm 0.65$ & $1.12 \pm 0.33$ & $2.12 \pm 0.59^{\wedge}$ & $p<0.01$ & $p=0.02$ \\
\hline B. forsytus & $2.32 \pm 0.94$ & $1.41 \pm 0.56$ & $2.07 \pm 0.51$ * & $1.35 \pm 0.49$ & $1.94 \pm 0.50$ * & $1.17 \pm 0.39$ & $1.92 \pm 0.47^{\circ}$ & $p=0.01$ & $p=0.09$ \\
\hline L. casei & $2.24 \pm 1.05$ & $1.38 \pm 0.55$ & $1.76 \pm 0.70^{\circ}$ & $1.32 \pm 0.47$ & $1.75 \pm 0.60 *$ & $1.18 \pm 0.39$ & $2.67 \pm 0.51^{\wedge}$ & $p=0.02$ & $p=0.10$ \\
\hline L. salivarius & $2.5 \pm 1,05$ & $1.50 \pm 0.62$ & $1.95 \pm 0.65$ * & $1.35 \pm 0.48$ & $1.68 \pm 0.72$ & $1.15 \pm 0.36$ & $2.03 \pm 0.66^{\wedge}$ & $p=0.01$ & $p=0.08$ \\
\hline L. fermentum & $2.26 \pm 0.90$ & $1.38 \pm 0.55$ & $2.11 \pm 0.50$ * & $1.26 \pm 0.45$ & $1.75 \pm 0.49 *$ & $1.21 \pm 0.41$ & $2.19 \pm 0.46^{*}$ & $p=0.02$ & $p=0.12$ \\
\hline
\end{tabular}




\section{Discussion}

The xylitol salivary level increased after the use of both types of chewing gum; however, the $100 \%$ xylitol gum achieved the highest decrease, as expected. The results of the in vivo study run similarly to those available in literature [7-9]. Salivary xylitol concentrations were elevated for a short period of time (less than $15 \mathrm{~min}$ ) and then decreased, reaching almost the baseline level at the 25-min evaluation. Xylitol concentration levels in saliva using the $100 \%$ xylitol chewing gum did not decrease as linearly as using the $22 \%$ gum, but bimodally. This difference could be related to the different distribution of the polyol in the gum: in the $100 \%$ the highest amount of xylitol was included in the gum pellet, while in the $22 \%$ it was only contained in the hard coating, as described in materials and method. It is, therefore, reasonable to have a second peak concentration after some time from the start of chewing. The sampling technique, stimulated and unstimulated saliva, was postulated as the reason of the bimodal fashion release concentration [7]. In this study, the second peak was observed at the end of the chewing period; chewing saliva stimulation is reduced after $5 \mathrm{~min}$ and this may have influenced the presence of the bimodal release concentration; as reported in literature, the highest salivary concentration of drugs (fluoride, nicotine, etc) released from gums was detected between 5 and $10 \mathrm{~min}$ from the beginning of use [26-29].

On the other hand, the skewed distribution of the salivary Xylitol concentration must be taken into account since high inter-subject variability has been observed. This outcome can be explained by several parameters, such as chewing distance, chewing frequency, and the twisting motion of the gum affecting the xylitol release [29]. These parameters were not included in the analysis as subjects were free to chew as they usually do.

A relatively high daily dose of xylitol is necessary to obtain positive effects [3-6,11-14,30-36]. The frequency of administration is also considered an important factor, since, as reported in this study, its concentration in saliva tends to decrease in a short time. The hypothesis that Xylitol may have an effect on dental plaque is related to the transport and phosphorylation of the polyol through the cell wall by a constitutive fructose-PTS (phosphotransferase) system with accumulation of xylitol-5-phosphate in intracellular substrate $[35,37]$. Whilst the current study was conducted in vitro using a pooled sub-gingival plaque sample, significant differences in antibacterial composition were detected using both chewing gums, although most impressive antibacterial actions were observed with the $100 \%$ gum. The bacterial viability is reduced over the time of the experiment $(24 \mathrm{~h})$, and it was similar in both groups, and the difference observed has to be mainly ascribed to the different concentration of xylitol in the gums. Few studies have focused on the effect of polyols on oral bacteria apart from cariogenic ones $[11,31,38]$. Xylitol proved to clinically reduce the amount of dental plaque and gingivitis in children and young adults [34,36,39]. In vivo, xylitol chewing gum was able to decrease mutans streptococci levels [39], while in vitro, Xylitol has shown to inhibit the growth of several bacterial strains like Streptococcus mutans, Streptococcus sobrinus, Lactobacillus rhamnosus, Actinomyces viscosus, Porphyromonas gingivalis, and Fusobacterium nucleatum $[32,37,38,40]$ with different effect on different strains. Xylitol is able to inhibit the production of inflammatory and proinflammatory cytokines derived from periodontal bacteria as Porphyromonas gingivalis and Aggregatibacter actinomycetemcomitans [13,40-42].

This study has potential limitations. First of all, it is necessary to consider the single administration in the in vivo phase of the study. It is likely that the use of the gums several times a day may also modify the amount of Xylitol in the mouth over a longer period. A trial that examines the use of gum for prolonged periods is necessary to support this hypothesis. Taking also into account the high variability in the salivary concentration of Xylitol observed among the different subjects, it would be useful to repeat the study involving a higher sample.

A third limitation could be the detection method used (spectrophotometry), different from those used in other studies (High-performance liquid chromatography or enzymatic assay using a polyol dehydrogenase-based procedure), which makes the present findings quite difficult to compare to the previous ones $[13,16,41]$. In favor of the test method used here, is that spectrophotometry detects lower levels of xylitol $(0.1 \mathrm{~g} / \mathrm{mL})$ than the other two. 
A further limit could be the study design of the in vitro part: it does not reflect real life conditions. The bacterial effect was measured with a continuous and direct contact between the xylitol solution derived from the two chewing gums and the bacteria strains for a period that does not reflect the real situation.

Diversely, this is the first paper, to the authors' knowledge, which evaluates and describes an antibacterial effect of xylitol-containing chewing gums on multiple strains in a pooled sub-gingival plaque sample.

\section{Conclusions}

Xylitol is a well-known caries preventive agent when applied via chewing gum. This study reports data on the in vivo salivary concentration of xylitol after the use of chewing gums, containing different amounts of the polyol, and the in vitro activity of the same types of chewing gum against a spectrum of oral bacteria.

The use of both types of chewing gum increased the xylitol salivary concentrations for a short period of time with a statistically significantly higher level using the $100 \%$ xylitol gum. The bacterial strains related to caries and periodontal disease from sub-gingival plaque were reduced in vitro by the two xylitol chewing gums with a higher and long-lasting reduction for the $100 \%$ xylitol gum. This study opens up to the use of xylitol against periodontal disease.

Supplementary Materials: The following are available online at http://www.mdpi.com/2076-3417/10/8/2900/s1, Date set.

Author Contributions: F.C., G.C., and M.G.C., designed, planned the study; F.C. and O.M. performed the sampling and the analysis; F.C., G.C., and M.G.C. wrote the manuscript draft, revised the statistical analysis, and created the tables; F.C. performed the literature searches; All the authors contributed to the discussion of the results and the revision of the manuscript. All authors have read and agreed to the published version of the manuscript.

Funding: All persons that took part in the study are mentioned as authors. This research received no specific grant from any funding agency in public, commercial, or not-for-profit sectors.

Acknowledgments: The authors would like to thank both the dental students and the volunteers that agreed to participate in the study.

Conflicts of Interest: The authors declare no conflict of interest.

\section{References}

1. Marsh, P.D. Are dental diseases examples of ecological catastrophes? Microbiology 2003, 149, 279-294. [CrossRef]

2. Chi, D.L.; Scott, J.M. Added Sugar and Dental Caries in Children: A Scientific Update and Future Steps. Dent. Clin. 2019, 63, 17-33.

3. Salli, K.; Lehtinen, M.J.; Tiihonen, K.; Ouwehand, A.C. Xylitol's Health Benefits beyond Dental Health: A Comprehensive Review. Nutrients 2019, 11, 1813. [CrossRef] [PubMed]

4. Söderling, E.M. Xylitol, mutans streptococci, and dental plaque. Adv. Dent. Res. 2009, 21, 74-78. [CrossRef]

5. Campus, G.; Cagetti, M.G.; Sale, S.; Petruzzi, M.; Solinas, G.; Strohmenger, L.; Lingström, P. Six months of high-dose xylitol in high-risk caries subjects-a 2-year randomised, clinical trial. Clin. Oral. Investig. 2013, 17, 785-791. [CrossRef] [PubMed]

6. Tanzer, J.M.; Thompson, A.; Wen, Z.T.; Burne, R.A. Streptococcus mutans: Fructose Transport, Xylitol Resistance, and Virulence. J. Dent. Res. 2006, 85, 369-373. [CrossRef] [PubMed]

7. Riedy, C.A.; Milgrom, P.; Ly, K.A.; Rothen, M.; Mueller, G.; Hagstrom, M.K. A surrogate method for comparison analysis of salivary concentrations of Xylitol-containing products. BMC Oral Health 2008, 8, 5. [CrossRef] [PubMed]

8. Tapiainen, T.; Renko, M.; Kontiokari, T.; Uhari, M. Xylitol concentrations in the saliva of children after chewing xylitol gum or consuming a xylitol mixture. Eur. J. Clin. Microbiol. Infect. Dis. 2002, 21, 53-55. [CrossRef]

9. Lif Holgerson, P.; Stecksén-Blicks, C.; Sjostrom, I.; Oberg, M.; Twetman, S. Xylitol concentrations in saliva and dental plaque after use of various xylitol-containing products. Caries Res. 2006, 40, 393-397. [CrossRef] 
10. Rafeek, R.; Carrington, C.V.F.; Gomez, A.; Harkins, D.; Torralba, M.; Kuelbs, C. Xylitol and sorbitol effects on the microbiome of saliva and plaque. J. Oral. Microbiol. 2018, 11, 1536181. [CrossRef]

11. Söderling, E.; Hirvonen, A.; Karjalainen, S.; Fontana, M.; Catt, D.; Seppä, L. The effect of xylitol on the composition of the oral flora: A pilot study. Eur. J. Dent. 2001, 5, 24-31. [CrossRef]

12. Kayalvizhi, G.; Nivedha, D.; Sajeev, R.; Prathima, G.S.; Suganya, M.; Ramesh, V. Evaluating the Efficacy of Xylitol Wipes on Cariogenic Bacteria in 19- to 35-month-old Children: A Double-blind Randomized Controlled Trial. Int. J. Clin. Pediatr. Dent. 2018, 11, 13-17. [CrossRef] [PubMed]

13. Han, S.J.; Jeong, S.Y.; Nam, Y.J.; Yang, K.H.; Lim, H.S.; Chung, J. Xylitol inhibits inflammatory cytokine expression induced by lipopolysaccharide from Porphyromonas gingivalis. Clin. Diagn. Lab. Immunol. 2005, 12, 1285-1291. [CrossRef] [PubMed]

14. Kim, S.; Park, M.H.; Song, Y.R.; Na, H.S.; Chung, J. Aggregatibacter actinomycetemcomitans-Induced AIM2 Inflammasome Activation Is Suppressed by Xylitol in Differentiated THP-1 Macrophages. J. Periodontol. 2016, 87, e116-e126. [CrossRef] [PubMed]

15. Beutler, H.O. Xylitol. In Methods of Enzymatic Analysis; Bergmeyer, H.U., Ed.; VCH Publishers Ltd.: Cambridge, UK, 1988; pp. 484-490.

16. Loesche, W.J.; Hockett, R.N.; Syed, S.A. The predominant cultivable flora of tooth surface plaque removed from institutionalized subjects. Arch. Oral. Biol. 1972, 17, 1311-1325. [CrossRef]

17. Song, X.; Yaskell, T.; Klepac-Ceraj, V.; Lynch, M.C.; Soukos, N.S. Antimicrobial action of minocycline microspheres versus 810-nm diode laser on human dental plaque microcosm biofilms. J. Periodontol. 2014, 85, 335-342. [CrossRef] [PubMed]

18. Esteves-Oliveira, M.; Pasaporti, C.; Heussen, N.; Eduardo, C.P.; Lampert, F.; Apel, C. Rehardening of acid-softened enamel and prevention of enamel softening through CO2 laser irradiation. J. Dent. 2011, 39, 414-421. [CrossRef]

19. Haffajee, J.A.; Uzel, N.G.; Goodson, J.M. Use of checkerboard DNA-DNA hybridization to study complex microbial ecosystems. Oral. Microbiol. Immunol. 2004, 19, 352-362.

20. Slots, J.; Slots, H. Bacterial and viral pathogens in saliva: disease relationship and infectious risk. Periodontology 2000 2011, 55, 48-69. [CrossRef]

21. Socransky, S.S.; Haffajee, A.D.; Smith, C.; Martin Paster, B.J.; Dewhirst, F.E.; Levin, A.E. “Checkerboard” DNA-DNA hybridization. Biotechniques 1994, 17, 788-792.

22. Alvim, D.C.S.S.; Ferreira, A.F.M.; Leal, M.A.; Oliveira, L.M.A.; Botelho, A.M.N.; Botelho, A.C.N.; Figueiredo, A.M.S.; Fracalanzza, S.E.L.; Teixeira, L.M.; Pinto, T.C.A. Biofilm production and distribution of pilus variants among Streptococcus agalactiae isolated from human and animal sources. Biofouling 2019, 35, 938-944. [CrossRef] [PubMed]

23. Contardo, M.S.; Díaz, N.; Lobos, O.; Padilla, C.; Giacaman, R.A. Oral colonization by Streptococcus mutans and its association with the severity of periodontal disease in adults. Rev. Clin. Period. Implantol. Rehabil. Oral. 2011, 4, 9-12. [CrossRef]

24. Mannaa, A.; Carlén, A.; Campus, G.; Lingström, P. Supragingival plaque microbial analysis in reflection to caries experience. BMC Oral Health 2013, 13, 5. [CrossRef] [PubMed]

25. Mannaa, A.; Carlén, A.; Dahlén, G.; Lingström, P. Intra-familial comparison of supragingival dental plaque microflora using the checkerboard DNA-DNA hybridisation technique. Arch. Oral. Biol. 2012, 57, 1644-1650. [CrossRef]

26. Gajendran, J.; Kraemer, J.; Langguth, P. In vivo predictive release methods for medicated chewing gums. Biopharm. Drug Dispos. 2012, 33, 417-424. [CrossRef]

27. Sjögren, K.; Lingström, P.; Lundberg, A.B.; Birkhed, D. Salivary fluoride concentration and plaque $\mathrm{pH}$ after using a fluoride-containing chewing gum. Caries Res. 1997, 31, 366-372. [CrossRef]

28. Bijella, M.F.; Brighenti, F.L.; Buzalaf, M.A. Fluoride kinetics in saliva after the use of a fluoride-containing chewing gum. Braz. Oral Res. 2005, 19, 256-260. [CrossRef]

29. Dawes, C.; Macpherson, L.M. Effects of nine different chewing-gums and lozenges on salivary flow rate and pH. Caries Res. 1992, 26, 176-182. [CrossRef]

30. Alanzi, A.; Soderling, E.; Varghese, A.; Honkala, E. Xylitol Chewing Gums on the Market: Do They Prevent Caries? Oral Health Prev. Dent. 2016, 14, 459-466.

31. Badet, C.; Furiga, A.; Thébaud, N. Effect of xylitol on an in vitro model of oral biofilm. Oral Health Prev. Dent. 2008, 6, 337-341. 
32. Marya, C.M.; Taneja, P.; Nagpal, R.; Marya, V.; Oberoi, S.S.; Arora, D. Efficacy of Chlorhexidine, Xylitol, and Chlorhexidine + Xylitol against Dental Plaque, Gingivitis, and Salivary Streptococcus mutans Load: A Randomised Controlled Trial. Oral Health Prev. Dent. 2017, 15, 529-536.

33. Milgrom, P.; Ly, K.A.; Rothen, M. Xylitol and its vehicles for public health needs. Adv. Dent. Res. 2009, 21, 44-47. [CrossRef] [PubMed]

34. Milgrom, P.; Ly, K.A.; Roberts, M.C.; Rothen, M.; Mueller, G.; Yamaguchi, D.K. Mutans streptococci dose response to xylitol chewing gum. J. Dent. Res. 2006, 85, 177-181. [CrossRef] [PubMed]

35. Trahan, L.; Bareil, M.; Gauthier, L.; Vadeboncoeur, C. Transport and phosphorylation of xylitol by a fructose phosphotransferase system in Streptococcus mutans. Caries Res. 1985, 19, 53-63. [CrossRef] [PubMed]

36. Twetman, S. Consistent evidence to support the use of xylitol- and sorbitol-containing chewing gum to prevent dental caries. Evid. Based Dent. 2009, 10, 10-11. [CrossRef] [PubMed]

37. Zou, Y.; Lee, Y.J.; Huh, J.; Park, J.W. Synergistic effect of xylitol and ursolic acid combination on oral biofilms. Restor. Dent. Endod. 2004, 39, 288-295. [CrossRef] [PubMed]

38. Shyama, M.; Honkala, E.; Honkala, S.; Al-Mutawa, S.A. Effect of xylitol candies on plaque and gingival indices in physically disabled school pupils. J. Clin. Dent. 2006, 17, 17-21.

39. Shinga-Ishiharaa, S.; Nakaia, Y.; Milgrom, P.; Söderling, E.; Tolvanen, M.; Murakami, K. Xylitol Carry-over Effects on Salivary Mutans Streptococci after 13 Months of Chewing Xylitol Gum. Caries Res. 2012, 46, 519-522. [CrossRef]

40. Park, E.; Na, H.S.; Kim, S.M.; Wallet, S.; Cha, S.; Chung, J. Xylitol, an anticaries agent, exhibits potent inhibition of inflammatory responses in human THP-1-derived macrophages infected with Porphyromonas gingivalis. J. Periodontol. 2014, 85, e212-e223. [CrossRef]

41. Oscarson, P.; Lif Holgerson, P.; Sjöström, I.; Twetman, S.; Stecksén-Blicks, C. Influence of a low xylitol-dose on mutans streptococci colonisation and caries development in preschool children. Eur. Arch. Paediatr. Dent. 2006, 7, 142-147. [CrossRef]

42. Wåler, S.M.; Assev, S.; Rölla, G. Xylitol 5-P formation by dental plaque after 12 weeks' exposure to a xylitol/sorbitol containing chewing gum. Scand. J. Dent. Res. 1992, 6, 319-321. [CrossRef] [PubMed]

(C) 2020 by the authors. Licensee MDPI, Basel, Switzerland. This article is an open access article distributed under the terms and conditions of the Creative Commons Attribution (CC BY) license (http://creativecommons.org/licenses/by/4.0/). 